\title{
Foreword
}

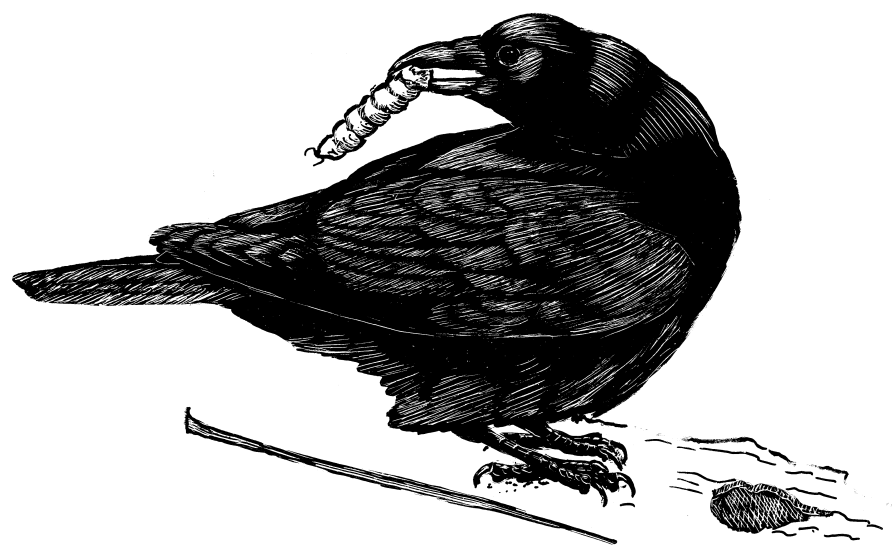

T $\mathrm{n}$ a world of disappearing biodiversity, enormous attention has been paid

1 to the impacts on birds of growing numbers of people and accelerating consumption. From the Dodo to the Ivory-billed Woodpecker to, now, Indian vultures, people have been concerned with the extermination of beautiful and interesting creatures, many of which play key roles in supplying vital ecosystem services to humanity. But relatively little attention has been paid to the other side of the coin, the manifold influences some groups of birds have had on human culture. In the Company of Crows and Ravens helps to redress the balance-and in the process gives us a splendid overview of this group of intelligent birds.

Members of the crow family are, perhaps second only to House Sparrows and the pigeon, the most prominent features of urban landscapes in much of the world. And they are infinitely more interesting than most of 
our other avian close companions. They are much favored by human activities. We create the roadkills and garbage that they love to devour. They are even likely to snatch your fast-food hamburger from the picnic table, undeterred by its lethal fat content. And human suppression of many of the raptors that would devour them makes cities and agricultural areas relatively safe havens, especially since they are more than smart enough to outwit people with shotguns. Crows, ravens, and Rooks, of course, are themselves vigorous predators and competitors-by helping them prosper, we heighten the jeopardy of more specialized bird species.

Not only do corvids tend to thrive in human-made environments, but they have also penetrated our psyches. Scarecrows have become characters in fiction and "Maître Corbeau" teaches us lessons in proper behavior. We "eat crow," climb to the "crow's nest," tear things apart with a "crowbar," and are "ravenous" after a long hike without food. Many human groups have considered them gods. The high intelligence and humanoid behavior of these birds have long fascinated biologists, and have resulted in some wonderful accounts of the comportment of individual species by, among others, Professor Bernd Heinrich of the University of Vermont. But this book is the first to produce a grand overview of the human-corvid complex and is truly something to crow about.

With any luck In the Company of Crows and Ravens will stimulate more people to connect with nature by enjoying the antics of these easily observed birds, and learning about them and about the complexities of nature in the process. If people can only learn to appreciate biodiversity in the process, then they will join the growing numbers who look at the paving over and plowing under of natural habitats and quote the raven-"nevermore."

\section{Paul Ehrlich}

